\title{
A EXPERIÊNCIA DA FAMÍLIA AO CONVIVER COM A FAMÍLIA DOENÇA CRÔNICA DA CRIANÇA
}

\author{
THE FAMILY EXPERIENCE OF LIVING WITH THE \\ CHILD'S CHRONIC ILLNESS
}

Elaine Buchhorn Cintra Damião* Margareth Angelo**

DAMIÃO, E.; ANGELO, M. A experiência da família ao conviver com a doença crônica da criança. Rev Esc Enf USP, v.35, n. 1, p. 66-71, mar. 2001.

\begin{abstract}
RESUMO
Esta pesquisa objetivou compreender como a família vivencia os periodos de dificuldades impostos pela doença crônica da criança. Utilizou-se como método de pesquisa a Teoria Fundamentada nos Dados e como referencial teórico o Interacionismo Simbólico. Foram entrevistadas famílias de crianças com doença crônica, fibrose cística do pâncreas e diabetes, possibilitando desvelar o processo vivenciado e o significado atribuído pela família a sua experiência. Os dados foram analisados até a fase de categorização dos significados, tendo emergido o fenômeno: "Sendo Difícil Não Ter Controle".
\end{abstract}

PALAVRAS-CHAVE: Criança. Doença crônica. Enfrentamento. Enfermagem da família.

\begin{abstract}
This research has focused on the family meaning of having a child with chronic illness. The Grounded Theory and the Symbolic Interactionism were employed as research method and theoretical approach respectively. The interviews involved families with children diagnosed as having a chronic disease, cystic fibrosis and diabetes, aiming to study the way the family copes with this situation, and the meaning giving by the family to this experience. Data were analyzed until the phase of categorizing and the phenomenon disclosed was: "Being hard not to have control".
\end{abstract}

KEYWORDS: Child. Chronic disease. Coping. Family nursing.

\section{INTRODUÇÃO}

Cuidar da criança com doença crônica é uma experiência muito dificil para a família, ainda mais quando a doença tem um prognóstico fechado e baixa expectativa de vida. Notávamos ao atender as famílias, que para algumas delas, cuidar da criança era muito penoso e triste. Parecia que a família já estava elaborando o luto, mesmo antes da morte da criança. Outras famílias, no entanto, enfrentavam a doença, davam suporte para a criança, parecendo mais estruturadas.

Segundo MUSCARI (1998), Doença crônica é definida como uma condição que afeta as funções do indivíduo em suas atividades diárias por mais de três meses, causa hospitalização durante um mês por ano ou requer o uso de dispositivos especiais de adaptação. Assim, a criança tem a vida irreversivelmente alterada pelos tratamentos e conseqüências impostos pela doença, tornando-se uma experiência multidimensional tanto para ela como para sua família. O ajustamento à situação também acontece de modo diferenciado, em tipo e intensidade, dependendo do estágio do ciclo de vida em que a família se encontre (WOODS; YATES; PRIMONO, 1989, HOLMAN; LORIG, 2000).

Há na literatura estudos clássicos sobre doença crônica, como o realizado por FORTIER; WANLASS (1984), que propôs cinco estágios seqüenciais para a família da criança deficiente: impacto, negação, luto,

* Professora Assistente do Departamento de Enfermagem Materno-Infantil e Psiquiátrica da Escola de Enfermagem USP. Doutoranda em Enfermagem pela EEUSP. Membro do GEENF - Grupo de Estudos em Enfermagem e Familia. E-mail: buchhorn@usp.br

* Professor Titular do Departamento de Enfermagem Materno-Infantil e Psiquiátrica da Escola de Enfermagem USP. Coordenadora do GEENF - Grupo de Estudos em Enfermagem e Família. 
enfoque externo e encerramento. HYMOVICH (1981, 1983) desenvolveu um instrumento que permitia avaliar o impacto da doença crônica ou deficiência da criança sobre a família e identificar as estratégias de enfrentamento utilizadas pelos pais. COPELAND pesquisou famílias de crianças com fibrose cística do pâncreas $(\mathrm{FC})$, diabetes juvenil e câncer, tendo estudado os períodos de desequilíbrio familiar causados pela situação de doença da criança (CLEMENTS; COPELAND; LOFTUS, 1990, COPELAND, 1993, COPELAND; CLEMENTS, 1993). Outros autores vêm desenvolvendo estudos sobre como a família responde à situação de doença, particularmente aquela que possui um membro com uma patologia crônica, surgindo o conceito de normalização, que pode ser entendido como um processo cognitivo e de estratégias de comportamento que visam a manter a vida da família o mais próximo possivel da normalidade (DEATRICK, J. A.; KNAFL, K. A.; WALSH, M., 1988; DEATRICK, J. A.; KNAFL, K. A., 1990; KNAFL, K. A.; DEATRICK, J. A., 1990; KNAFL, K. A.; BREITMAYER, B.; GALLO, A.; ZOELLER, L., 1996; DEATRICK, J. A.; KNAFL, K. A.; MURPHY MOORE, C., 1999).

Refletindo sobre os trabalhos existentes na literatura e no atendimento prestado à família, percebíamos que faltava um elo que explicasse a melhor ou pior adaptação da família à situação de doença crônica. Parecia haver alguma coisa a mais sobre a experiência da família, em como a família da criança com doença crônica a vivencia. As questões nos incomodavam, porém não conseguiamos obter as respostas necessárias somente na literatura. Continuávamos a nos perguntar: como algumas famílias parecem estar bem adaptadas à situação de doença da sua criança? Como as famílias experienciam os períodos de dificuldade impostos pela doença? Será que os pais não queriam saber mais do que orientações, informações sobre o tratamento e distribuição de medicamentos durante a consulta de enfermagem? Não que estas orientações sejam destituídas de importância, porém podem ser grandemente ampliadas em sua profundidade e na utilização de novas abordagens. (DAMIÃO, 1992, 1997; ELSEN; PATRÍCIO, 1989).

Portanto, tornei-me motivada a conhecer a experiência da família da criança com doença crônica, tendo como objetivo: Compreender como a família vivencia os periodos de dificuldades impostos pela doença crônica da criança.

\section{REFERENCIAL TEÓRICO E METODOLÓGICO}

As metodologias qualitativas interpretativas de investigação são as que melhor se adequam a apreender as ações do processo vivenciado pela família, detectando os aspectos aos quais ela dá sentido. A Teoria Fundamentada nos Dados é uma das metodologias mais representativas deste grupo e que tem como referencial teórico o Interacionismo Simbólico (ANGELO, 1997).

O Interacionismo Simbólico é uma teoria sobre o comportamento humano e se fundamenta no pressuposto de que a experiência humana é mediada pela interpretação. Isto é, o ser humano confere significado aos objetos com os quais interage e direciona seus atos em função destes significados. Neste sentido, o fenômeno deve ser compreendido através da perspectiva dos participantes e deriva das interações por eles estabelecidas (CHARON, 1989).

A Teoria Fundamentada nos Dados, consiste numa forma de estudar fenômenos, desenvolvido conceitualmente através de um processo de coleta e de análise de dados sistematicamente conduzido. O resultado de todo o processo é uma teoria emergente das relações estabelecidas entre os conceitos descobertos (ANGELO, 1997).

\section{Caminho Metodológico}

AS FAMÍLIAS. As familias desta pesquisa foram contatadas diretamente pela pesquisadora, havendo colaboração da APAM (Associação Paulista de Assistência a Mucoviscidose) e de pessoas que conheciam famílias que tinham uma criança com doença crônica e que forneceram nomes e telefones para contato. Todas famílias contatadas concordaram em participar, perfazendo um total de seis famílias nucleares de crianças com diagnóstico de doença crônica (fibrose cística e diabetes), confirmado há pelo menos um ano, a fim de que já tivessem tido alguma experiência em relação à situação de doença. Foram entrevistados seis mães e dois pais.

COLETANDO DADOS. Foram realizadas entrevistas semi-estruturadas, e cada familia foi entrevistada somente uma vez, não sendo necessários esclarecimentos posteriores. A participação no estudo foi voluntária, garantindo-se a privacidade da família e da criança e o sigilo das informações obtidas. As entrevistas foram gravadas, tendo as seguintes questões norteadoras:

1.Você poderia me falar sobre a ocasião mais dificil que a família viveu desde que soube que tinha alguma coisa errada com seu filho?

2.0 que o ajudou a atravessar esta ocasião dificil na época em que aconteceu?

3.Como você se sente hoje ao viver uma situação dificil em relação à primeira dificuldade durante a doença do seu filho? 
ANALISANDO OS DADOS. Inicialmente, foi realizada a transcrição fiel das fitas gravadas, sendo também anotados, como dados de observação, as entonações da fala do sujeito assim como o seu comportamento não verbal. Após a leitura exaustiva das transcrições, realizou-se a codificação aberta e sua categorização, segundo preconizado por GLASER; STRAUSS (1967). Embora a Teoria Fundamentada nos Dados vise a proposição de um modelo teórico, este estudo pretendeu a descrição de categorias de significados, que mediante o processo de comparação constante, permitiu a identificação de um fenômeno.

\section{RESULTADOS}

A experiência da família caracterizou-se pelo fenômeno: "SENDO DIFÍCIL NÃO TER CONTROLE". Este fenômeno representa a dificuldade e o sofrimento da família em vivenciar a doença crônica da criança e explica a falta de controle da situação que ocorre, principalmente, nos momentos de crise.

O choque da descoberta é muito forte, a família apesar de estar buscando saber o porquê da criança não estar bem, nunca espera que o diagnóstico seja uma doença séria e incurável. Este é um dos momentos, onde a família sente-se completamente fora do controle da situação vivida: ela não sabe o que é a doença; não conhece quais são as conseqüências; não sabe qual é o tratamento, ou se existe tratamento; não sabe no que vai implicar para o dia a dia da família e da própria criança. A família não consegue saber se conseguirá continuar vivendo com o sofrimento e se ela terá condições de ajudar a criança. Portanto, a fase mais dificil para a família, é aquela na qual o descontrole da situação vivida é maior ou mesmo total.

O fenômeno, por conseguinte, é composto pelas categorias, "Tentando ter controle da situação inicial da doença da criança", "Tentando manter algum controle sobre os efeitos da doença", "Não conseguindo ter controle da situação de doença", "Conseguindo ter algum controle da situação atual de doença da criança" e suas subcategorias que nos permitem compreender a dimensão da falta de controle experenciada em relação à doença crônica, a organização da família em busca do equilíbrio e as estratégias de enfrentamento utilizadas na situação, a fim de que a vida possa prosseguir.

\section{Tentando ter controle da situação inicial da doença da criança}

Inicialmente, a familia, ao perceber que a criança não está bem, se mobiliza para descobrir o que está acontecendo de errado com a criança. Para a família, que está buscando descobrir a doença, muitas vezes saber o que a criança tem é um alívio. Por outro lado, a família percebe-se não conseguindo acreditar no diagnóstico dado pelo médico. É dificil aceitar que a sua criança tem uma doença grave.

\subsection{Tentando ter controle através da busca do conhecimento}

"Eu pedi pro médico que me desse alguma coisa para ler. Algumas matérias, alguma coisa assim, que precisava saber o que é que era a doença".

Ao aceitar que há alguma coisa errada com a criança, a família percebe que precisa retomar o controle da situação. Nesse sentido, a família quer conhecer mais sobre a doença e manter-se atualizada sobre ela, porque isto irá ajudá-la a controlar a doença da sua criança e esclarecer suas dúvidas sobre todos os aspectos da doença.

Os sentimentos nesse momento são principalmente de incredulidade, desespero, revolta e culpa. É dificil para a família aceitar a doença, porque além de causar a falta de controle da situação atual, irá causar, ainda, a falta de controle da família sobre o futuro da criança.

\subsection{Vivenciando o sofrimento da situação inicial da doença da criança}

"Eu pensei que eu descobrindo a doença, que o mundo ali tivesse desabado naquele instante e que eu não fosse ter forças para conduzir, pra ir avante com o tratamento do meu filho".

A família está apenas no início do seu processo de aceitação e convivência com a doença, não conseguindo ter uma visão ampla e realista do que significa e significará a doença crônica da criança, suas conseqüências e tratamentos.

Esta etapa do processo é caracterizada pelas categorias e subcategorias seguintes, que revelam o movimento da família na tentativa de aceitar e administrar a doença da criança. A vivência torna-se mais dificil ou mais fácil dependendo do controle que a família consegue exercer sobre a situação específica que está sendo vivida naquele momento.

\section{Tentando manter algum controle sobre os efeitos da doença}

A familia ao perceber, que não tem mais o controle da situação de vida, busca restabelecê-lo, tentando retomar a normalidade dentro da família. Primeiramente a família procura conhecer mais sobre o tratamento da doença que deve ser bom e iniciado com urgência, visando a melhora das condições da criança.

Esta categoria também engloba as estratégias de enfrentamento utilizadas pela família para conviver 
e administrar a doença crônica da criança. A família poderá sair vencedora, tendo o controle da situação da doença, se souber usar as armas do conhecimento e do enfrentamento; se não souber, se não conseguir adquirir o controle, a família passará de situação dificil para outra, vivendo em função da doença e sendo controlada por ela.

\subsection{Tendo que ter controle do cuidado da criança}

"Mudou porque eu tive que aprender, tanto a cozinhar para ela, a lidar com adoçante, fazer suco...".

O primeiro passo da família é inteirar-se do tratamento da doença da criança e conseqüentemente aprender a ter o domínio do cuidar. Ao adquirir a autonomia do cuidar da criança com doença crônica, a familia, também, percebe que é possivel conviver com a doença.

\subsection{Não sendo vencida pela doença}

"Eu não me dou o direito de sofrer, porque eu acho assim, que o pior é ele".

Conviver com a doença crônica não é tarefa fácil. A família inicia sua instrumentalização para a batalha diária através da utilização das estratégias de enfrentamento que lhe permitem não ser vencida e subjugada pela situação de doença da criança.

\subsection{Fornecendo suporte para a criança conviver com a criança}

"Então, eu acho que eu tenho que dar essa formação, que ela tem que controlar. E tipo um cachorrinho, que ela tem que conviver com este cachorrinho. Ela tem' que cuidar dessa doença, que a doença é dela. Por enquanto eu estou aqui, eu faço o que der... Mas ela tem mesmo que aprender... ".

Os pais também se preocupam com a criança doente e querem ajudá-la a superar e conviver com sua doença e conseqüências. A família, ainda, tem consciência que é a própria criança que tem que viver as dificuldades da doença. Esta conscientização é muito sofrida para a família porque ela percebe que não pode proteger a criança o tempo todo. Assim, a família implementa ações a fim de ter maior controle da situação atual de doença da criança, além de lhe dar condições para que controle sozinha sua própria doença mais tarde.

\subsection{Tentando manter o controle da situação familiar}

"Eu acho que mudou a família. Mudou muito! Tem a fase do antes e a fase do depois, entendeu? Não tem a fase do antes do sim e depois do sim? Agora tem a fase da diabetes... ".

As famílias ao utilizarem as estratégias de enfrentamento tornam-se mais unidas e fortes para conviverem e suportarem não só a criança com a doença crônica assim como a si mesmos. A família começa a perceber que agora nem tudo é novo e que pode adquirir algum controle sobre a situação de doença da criança. Percebe, também, que ela não era doente e sim a criança, alterando seu comportamento, tentando fazer com que seus outros membros tenham uma vida normal.

\section{Não conseguindo ter controle da situação de doença}

A família enfrenta e enfrentará muitas ocasiões dificeis, novas ou não, durante o curso da doença porque esta situação é própria da patologia crônica, fazendo parte da vivência da família. Nestes períodos a família se vê novamente perdida por estar fora do controle da situação.

\subsection{Vivenciando a falta de controle sobre os efeitos da doença}

"O R. com essas internações de repetição, um adolescente, não ia pra escola, já tava sentindo o drama, achando que ia repetir o ano, que ia morrer. Ele tava muito derrubado, não queria saber de nada".

A familia nestes momentos dificeis percebe quão penoso é enfrentar a doença sabendo que é incurável, vendo o sofrimento da criança, querendo estar no lugar da criança, quando esta sofre, reagudiza ou descompensa e reinterna. Esta categoria permeia toda a vida da família, porque a doença crônica tem períodos de exacerbação e de estabilidade de seus sinais e sintomas. A família vivencia estas fases como mais ou menos dificil dependendo do controle que ela já tenha adquirido sobre a doença.

\subsection{Vivenciando o cansaço da batalha}

"Agora está mais dificil, porque ela nunca teve tantas internações como agora. Então, acho que estou meio cansada de hospital, ficar, levar na consulta, fisioterapia, essas coisas. Eu já estou cansando, entendeu? Eu levo, faço tudo, mas cansa porque você batalha, batalha e você não vê um bom resultado. Você entende?".

Esta subcategoria retrata o desânimo da família. O tratamento em si também pode deixar a desejar porque todos os esforços feitos em função dele, não resultam numa resposta satisfatória. A resposta conseguida não é aquela que a familia sonha e espera, não é um resultado que satisfaça os pais.

\section{Conseguindo ter algum controle da situação atual de doença da criança}

A familia divide o seu tempo de viver em antes e depois do princípio da doença da criança. O antes é compreendido como a fase que se inicia quando a 
criança adoece, mesmo antes do diagnóstico, até a fase em que o diagnóstico é confirmado e o tratamento implementado. Nesta categoria encontramos o depois. Esta fase é considerada mais fácil ou menos dificil, porque a família sente que consegue exercer certo controle sobre a situação e que nem tudo é mais uma novidade.

\subsection{Conseguindo administrar a doença}

"A gente sente diferente porque é uma situação que a gente convive. Eu me sinto mais maduro sobre a doença dele. Porque hoje eu tenho um conhecimento maior do problema dele".

"Mas, é isso aí. Eu acho que eu tenho o domínio da situação sim!".

Com o passar do tempo, algumas famílias conseguem perceber que a doença crônica é administrável, que realmente é possivel conviver com ela e pensar num futuro para a criança. Outras famílias, ao vivenciarem a doença crônica conseguem não desanimar, mas percebem que o tratamento está prolongando a vida da criança com uma qualidade de vida melhor. O futuro parece realmente não existir ou não estar muito longe, porém a família, utilizandose das estratégias de enfrentamento, aceita a doença e domina esta situação com mais segurança e desenvoltura.

\subsection{Conseguindo ver um futuro para a criança}

"Eu espero realmente que ela aprenda isso, que aprenda a dar mais valor à vida, que viva super bem, tenha filhos. Hoje ela tem pai e mãe para dar insulina. Depois, quando ela arrumar um namorado pra casar, ela vai ter que ensinar ele a dar injeção, senão vou falar pra ele que não serve pra casar com minha filha".

Ao conseguir ter o dominio da situação de doença, a família se descobre pensando num futuro para a criança como se ela fosse saudável. Podemos perceber essa atitude da família, principalmente, diante daquelas doenças crônicas, que a própria história natural da doença permite que a família tenha um maior controle. A familia, nesses casos, entende que ao seguir o tratamento, a criança tem maiores e melhores chances de vida e vislumbra um futuro para ela.

\section{DISCUSSÃO}

O fenômeno "Sendo Difícil Não Ter Controle" nos permite compreender a experiência da família em ter uma criança com doença crônica. A necessidade da família em ter controle, isto é, sentirse segura ao cuidar da criança doente é o dado novo que surge e que explica o por quê da família não

conviver bem com a doença crônica. É a falta de 70 controle desta situação desconhecida para a família, que faz com que ela se sinta perdida e sem rumo.

As categorias significantes descritas acima vêm reforçar os resultados dos trabalhos de CANAM (1993), CLAWSON (1996), COYNE (1997) sobre a adaptação da família, as tarefas pertencentes a este processo adaptativo, bem como as estratégias de enfrentamento utilizadas pelos membros da família. Podemos observar nas categorias já descritas, três componentes do processo de adaptação da família: a) busca de conhecimento, isto é, estar motivado para adquirir e processar informações sobre a doença; b) aquisição de habilidades, ao aprender procedimentos e cuidados relativos à doença e c) recursos, tanto físicos como emocionais e financeiros (CANAM, 1993; CLAWSON, 1996; COYNE, 1997). Nas categorias SENDO DIFÍCIL NÃO TER CONTROLE TENTANDO TER CONTROLE DA SITUAÇÃO INICIAL DE DOENÇA DA CRIANÇA pudemos perceber a busca do conhecimento que a familia realiza tentando compreender melhor como a doença se processa. TENDO QUE TER CONTROLE DO CUIDADO DA CRIANÇA é a categoria que explica como a família deve se instrumentalizar adquirindo habilidades, antes desconhecidas, para poder cuidar de sua criança. Aqui, também, é descrito o último elemento deste processo, denominado recursos, fisicos, emocionais e financeiros. A família despende muito tempo e energia física e emocional no cuidado da criança, bem como o custo financeiro da doença, onerando as finanças da família e gerando falta de controle da situação.

Identificamos, também, nas categorias deste estudo, as tarefas de adaptação da família e as estratégias de enfrentamento utilizadas pela família, sendo semelhantes às descritas por CANAM (1993).

A categoria TENTANDO TER CONTROLE DA SITUAÇÃO INICIAL DA DOENÇA DA CRIANÇA retrata o impacto da família ao se defrontar com o fato que sua criança tem uma doença crônica. Sua primeira tarefa é, então, aceitar a condição da criança. Após conseguir controlar a situação inicial de doença, recuperando-se do primeiro impacto, a família está em condições de executar a tarefa seguinte. A categoria TENDO QUE TER CONTROLE DO CUIDADO DA CRIANÇA representa a vivência da família ao administrar o cuidado diário da criança. A família aprende como realizar cuidados específicos com a sua criança. Esta tarefa é bastante estressante para os pais porque eles devem aprender e desenvolver novas atividades para as quais eles não estavam preparados. Ao estar FORNECENDO SUPORTE PARA A CRIANÇA CONVIVER COMA DOENÇA, a família está realizando outra tarefa, que é encontrar as necessidades de desenvolvimento normal da criança. A família deve focalizar a criança, seu processo normal 
de desenvolvimento e não somente sua doença e conseqüências. Ainda há a necessidade da familia em dividir seu tempo e energias investidas na criança entre os demais membros da familia. Assim, encontrar as necessidades de desenvolvimento de seus outros membros é a tarefa representada pela categoria TENTANDO MANTER O CONTROLE SITUAÇÃO FAMILIAR.

As famílias que conseguem se adaptar, realizando as tarefas de adaptação e ao mesmo tempo utilizar-se das estratégias de enfrentamento, são as familias que sentem estar CONSEGUINDO TER ALGUM CONTROLE DA SITUAÇÃO ATUAL DA DOENÇA DA CRIANCA. Algumas famílias, porém, não conseguem adquirir o controle da situação de doença, não utilizando as estratégias de enfrentamento e não conseguindo executar as tarefas adaptativas da familia da criança com doença crônica. Esta circunstância é observada na categoria $N \tilde{A} O$ CONSEGUINDO TER CONTROLE SOBRE A SITUAÇÃO DE DOENÇA.

Portanto, o processo de adaptação das famílias não é estanque, podendo a família passar de um periodo de controle da situação para outro de falta de controle e retornar, novamente, a uma fase de controle da situação. O importante é que a familia não permaneça estagnada no meio do processo, sem conseguir avançar, sem conseguir crescer.

A família deve ser auxiliada e estimulada a adquirir o controle da situação de doença da sua criança, através da busca das suas próprias demandas e desafios em cada etapa do processo. Assim, a família pode se tornar mais bem adaptada e competente para cuidar da criança e conseguir administrar a situação, que toda a familia vivencia, com um sofrimento menos intenso.

\section{REFERÊNCIAS BIBLIOGRÁFICAS}

ANGELO, M. Com a familia em tempos dificeis - uma perspectiva de enfermagem. São Paulo, 1997. 117p. Tese (LivreDocência) - Escola de Enfermagem, Universidade de São Paulo.

CANAM, C. Common adaptive tasks facing parents of children with chronic conditions. J Adv Nurs, v.18, n.1, p.46-53, 1993.

CHARON, JM. Symbolic interactionism: an introduction, an interpretation, an integration. 3.ed. Englewood Cliffs, Prentice-Hall, 1989

CLAWSON, JA. A child with chronic illness and the process of family adaptation. J Pediatr Nurs, v.11, n.1, p.52-61, 1996.

CLEMENTS, DB.; COPELAND, LG.; LOFTUS, M. Critícal times for families with a chronically ill child. Pediatr Nurs, v.16, n.2, p.157-61, 1990 .
COPELAND, LG. Caring for children with chronic conditions: model of critical times. Holistic Nurs Pract, v.8, n.1, p.45-55, 1993.

COPELAND, LG.; CLEMENTS, DB. Parental perceptions and support strategies in caring for a child with a chronic condition. Issues Compr Pediatr Nurs, v.16, n.2, p.109-21, 1993.

COYNE, IL. Chronic illness: the importance of support for families caring for a child with cystic fibrosis. $\mathbf{J}$ of Clinic Nurs, v.6, n.2, p.121-9, 1997

DAMIÃO, EBC. Sendo difícil não ter controle: a família vivenciando a doença crônica da criança. São Paulo, 1997. 126p. Dissertação (Mestrado) - Escola de Enfermagem, Universidade de São Paulo.

DAMIÃO, EBC. Assistência de enfermagem a nivel ambulatorial a crianças portadoras de mucoviscidose In: CURSINO, M.R. et al (orgs.) Assistência de enfermagem em pediatria. São Paulo, Sarvier, 1992. p.203-5.

DEATRICK, JA.; KNAFL, KA. Management behaviors: Day-today adjustments to childhood chronic conditions. J Pediatr Nurs, v.5, n.1, p.15-22, 1990.

DEATRICK, JA.; KNAFL, KA.; MURPHY-MOORE，C. Clarifying the concept of normalization. Image $J$ Nurs Sch, v.31, n.3, p.209-14, 1999.

DEATRICK, JA.; KNAFL, KA.; WALSH, M. The process of parenting a child with a disability: Normalization through accommodation. JAdv Nurs, v.13, n.1, p.15-21, 1988.

ELSEN, I.; PATRÍCIO, ZM. Assistência à criança hospitalizada: tipos de abordagem e suas implicações para a enfermagem. In: SCHMITZ, E.M. et al. Pediatria e puericultura. São Paulo, Atheneu, 1989. cap.15, p.169-79.

FORTIER, LM.; WANLASS, RL. Family crisis following the diagnosis of a handicapped child. Family Relations, v.33, p.1324, 1984.

GLASER, B.; STRAUSS, A. The discovery of grounded theory. Chícago, Aldine, 1967.

HOLMAN, H.; LORIG, K. Patients as partners in managing chronic dísease. BMJ, v.320, p.526-7, 2000.

KNAFL, KA.; BREITMAYER, B.; GALLO, A.; ZOELLER, L. Family response to childhood chronic illness: Description of management style. J Pediatr Nurs, v.11, p.315-26, 1996.

KNAFL, KA.; DEATRICK, JA. Family management style: Concept analysis and development. J Pediatr Nurs, v.4, n.1, 1990.

MUSCARI, ME. Coping with cronic illness. AJN, v. 98, p. 20-2, 1998.

WOODS, NF.; YATES, BC.; PRIMOMO, J. Supporting families during chronic illness. Image J Nurs Sch, v.21, n.1, p. 46-50, 1989.

Artigo recebido em 08/05/00

Artigo aprovado em 13/08/01 